\title{
Convincing evidence for rapid ice sheet growth during the last glacial period
}

\author{
Mark Siddall ${ }^{1 *}$, E.J. Rohling ${ }^{2}$ and H.W. ARz ${ }^{3}$
}

'Department of Earth Sciences, University of Bristol, UK; siddall@Ideo.columbia.edu. ${ }^{2}$ National Oceanography Centre, Southampton, UK. ${ }^{3}$ Reserach Center for Geosciences, Potsdam, Germany. ${ }^{*}$ currently at Lamont-Doherty Earth Observatory, Pallisades, USA.

It is commonly assumed that ice sheet growth over a glacial cycle follows a sawtooth pattern of very slow ice-sheet growth during the glacial period and rapid loss during the glacial termination (see e.g., Imbrie et al. 1984; Huybers and Wunsch, 2004; Lisiecki and Raymo, 2005). However, this assertion is challenged by observations of sea level derived from Red Sea oxygen isotope records, which clearly and consistently show rates of sea level equivalent ice sheet growth of between 1-2 cm $\mathrm{yr}^{-1}$. Here, we review this evidence and consider the increasing amount of independent data supporting rapid rates of ice-sheet growth during Marine Isotope Stage (MIS) 3, around 60-30 kyr BP.

\section{The Red Sea sea level records}

The Red Sea is separated from the open ocean by Hanish Sill, which decreases in passage area by three orders of magnitude during periods of full glacial sea level lowering (Fig. 1). This means that (even today) the restricted exchange of waters between the Red Sea and the open ocean is extremely sensitive to sea level variations.

The Red Sea is subject to strong net evaporation. Evaporation strongly enhances oxygen isotope ratios in such marginal basins with limited communication to the open ocean because this enhancement of oxygen isotope ratios in the basin is linked not only to the rate of evaporation but also to the refreshment rate of water in the basin by exchange over the sill (the residence time of water in the basin) (Rohling, 1999). The longer the residence time, the longer the water is exposed to the high evaporation rates, and the heavier the isotope ratio becomes due to preferential evaporation of the lighter ${ }^{16} \mathrm{O}$ isotope.

Evaporative enhancement of oxygen isotope ratios and the great sensitivity to exchange over the sill (Fig. 1) strongly couple Red Sea oxygen isotope ratios with sea level. This is best exemplified by the full glacial-interglacial range of change in stable oxygen isotope ratios in water of 4.5-5\% (allowing for a $4^{\circ} \mathrm{C}$ glacial to interglacial temperature range (Arz et al., 2007)), compared to $\sim 1-1.2 \%$ in the open ocean (Thunell et al., 1988; Hemleben et al., 1996; Rohling et al., 1998; Fenton et al., 2000; Siddall et al., 2003; Arz et al., 2003).

Siddall et al. (2003) used a three-layer hydraulic model to calculate water-mass exchange at the sill (Siddall et al., 2002),

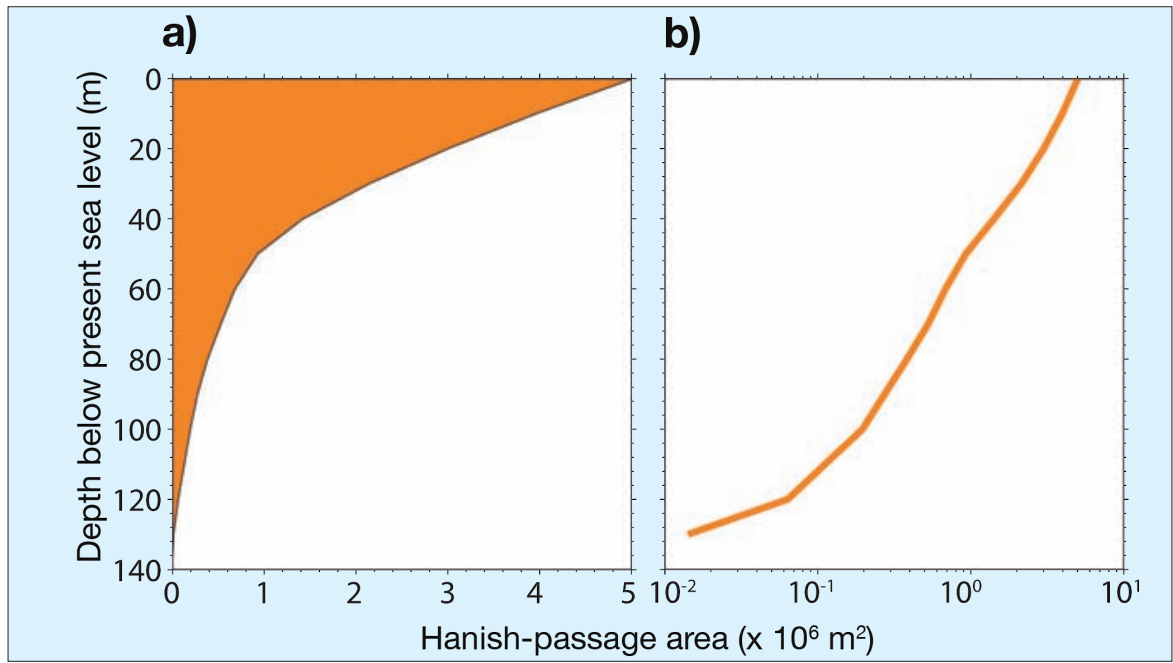

Figure 1: The Red Sea is separated from the open ocean by Hanish Sill, which is only $137 \mathrm{~m}$ deep (Werner and Lange, 1975; Rohling et al., 1998; Fenton et al., 2000; Siddall et al., 2002; 2003; 2004). Bathymetric data show that the sill passage narrows from $110 \mathrm{~km}$ to $\sim 6 \mathrm{~km}$ at $120 \mathrm{~m}$ below modern sea level. Narrowing of the sill passage with depth causes exponential decrease in sill passage area during glacial sea level lowering. Passage area of Hanish Sill with respect to water depth using $\boldsymbol{a}$ ) linear scale, and $\boldsymbol{b}$ ) logarithmic scale, emphasizing that passage area changes by 3 orders of magnitude. Note the large change in cross section in 0-120 m range of glacial to interglacial sea level. Due to magnitude of change over this range, the Red Sea is extremely sensitive to sea level change.

coupled to a model of oxygen isotope fractionation in an evaporative basin (Rohling, 1999). By varying sill depth in the model and assuming a $5^{\circ} \mathrm{C}$ temperature drop at the Last Glacial Maximum (LGM), a relationship was calculated between sea level and oxygen isotope ratios in the central Red Sea (for both water and calcite) (Siddall et al., 2003, 2004). This relationship was then used to calculate sea level fluctuations from Red Sea oxygen isotope records to within $\pm 12 \mathrm{~m}(2 \sigma)^{\#}$.

Recently, Arz et al. (2007) used temperature estimates from coccolithophore-based long-chain alkenone unsaturation ratios, in combination with benthic foraminifer-based oxygen isotope records from a core in the northernmost Red Sea, to estimate a seawater oxygen isotope record for MIS 3. This record was then empirically scaled to sea level using coral-based sea level estimates. An additional record was generated using the oxygen isotopes measured on foraminifers, without removing the temperature component. Benthic isotopes in the Red Sea may respond less quickly to varying sea level than those in planktic organisms and may, therefore, smooth out rapid variations in sea level. The Arz et al. (2007) reconstruction was further smoothed using a 5-point running mean.

\section{Comparison}

As the underlying mechanism of sea level forcing on Red Sea oxygen isotope ratios is the same for both the approach of Arz et al. (2007) and Siddall et al. (2003) there should be strong similarities between the different reconstructions. To facilitate comparison, Figure 2 plots all three records after transformation to a common (arbitrary) age scale. Despite their different regional origins, the different approaches followed in calibration and the different chronologies, these records show strikingly similar signal amplitudes. All demonstrate higher sea level during the early stages of MIS 3, with subsequently lower sea level during the latter stage (following the trend in summer insolation at $65^{\circ} \mathrm{N}$ ). All include four major sea level cycles within MIS 3, with amplitudes between 20-30 m-this compares well with the variability found from Huon Peninsula coral terraces (Chappell, 2002), and from the compilation of Thompson and Goldstein $(2005,2006)$. Figure 2 also shows the similarity to scaled open-ocean benthic isotope records (Cutler et al., 2003; Waelbroeck et al., 2002). The high degree of similarity is difficult to explain unless all records contain a strong, common sea level signal.

\section{Additional evidence}

Rates of ice-sheet loss reached an average of $1 \mathrm{~cm} \mathrm{yr}^{-1}$ during the last deglaciation, with peaks of up to 3-5 $\mathrm{cm} \mathrm{yr}^{-1}$ during so-called meltwater pulses (Fairbanks, 1989; Stanford et al., 2006). It is, therefore, not beyond reason to find evidence for similar rates of ice-sheet loss during preceding sea level 
cycles within MIS 3. High rates of ice-sheet growth are more controversial, largely because ice-sheet models have struggled to grow ice sheets rapidly (see e.g. Bintanja et al., 2002; Peltier, 2004). However, there is increasing independent evidence that high rates of ice-volume growth/sea level decrease were a reality. In addition to the Red Sea results, coral data indicate such high rates at the MIS 5-4 transition $(60 \mathrm{~m}$ in 6 kyr: Cutler et al., 2003; Thompson and Goldstein, 2005; 2006), the MIS 5e-5d transition (40 m in 4 kyr: Lambeck et al., 2002; Thompson and Goldstein, 2005; 2006), and during a reversal within the sea level rise of the penultimate deglaciation (40 $\mathrm{m}$ in $2 \mathrm{kyr}$ : Esat et al., 1999; Siddall et al., 2006; Thompson and Goldstein, 2005; 2006).

Recently reported data from Barbados also indicates rapid ice sheet growth during the MIS 3-2 transition (30 m in $3 \mathrm{kyr}$ : Peltier and Fairbanks, 2006). Furthermore, the glacio-isostatic ICE5G-V2 model has simulated such a rapid growth rate in the specific context of the growth of the West Keewatin Dome on the North American continent during the MIS 3-2 transition (Peltier and Fairbanks, 2006).

\section{Conclusion}

During MIS 3, cold Dansgaard-Oeschger (D-O) stadials lasted 2-3 kyr, and warm D-O interstadials 3-4 kyr. The cycles of warming (2-3 kyr) and cooling (2-3 kyr) in Antarctica lasted around 4-6 kyr. Ice volume is given by the integration of the rate of growth (1-2 $\mathrm{cm} \mathrm{yr}^{-1}$ ) or loss (1-5 $\left.\mathrm{cm} \mathrm{yr}^{-1}\right)$ over the duration of growth or loss (2-4 kyr). Regardless of which timing is preferred for the icevolume fluctuations (following either Antarctic or Greenland climate variability, see Rohling et al., 2004; Arz et al., 2007; Siddall et al., subm.), it is clear that independently observed rates of ice-volume growth, as well as the duration of cold versus warm periods during MIS 3 are more than adequate to give cycles of $30 \mathrm{~m}$ sea level equivalent ice sheet growth/loss during MIS 3 . We note that Greenland temperatures varied by as much as $75 \%$ of their glacial-interglacial amplitudes during MIS 3 (Huber et al., 2006), while Antarctic temperatures varied by $25 \%$ of the glacial-interglacial amplitude (EPICA community members, 2006). The suggested magnitude of MIS 3 sea level cycles here is $30 \mathrm{~m}-25 \%$ of the glacial to interglacial amplitude of $120 \mathrm{~m}$.

Finally, we note the intriguing relationship between the relative amplitudes during MIS 3 of the Antarctic temperature signal and the $\sim 30 \mathrm{~m}$ of sea level fluctuation suggested here-both being $25 \%$ of their glacial-interglacial amplitudes. This fact, combined with the existence of four sym-

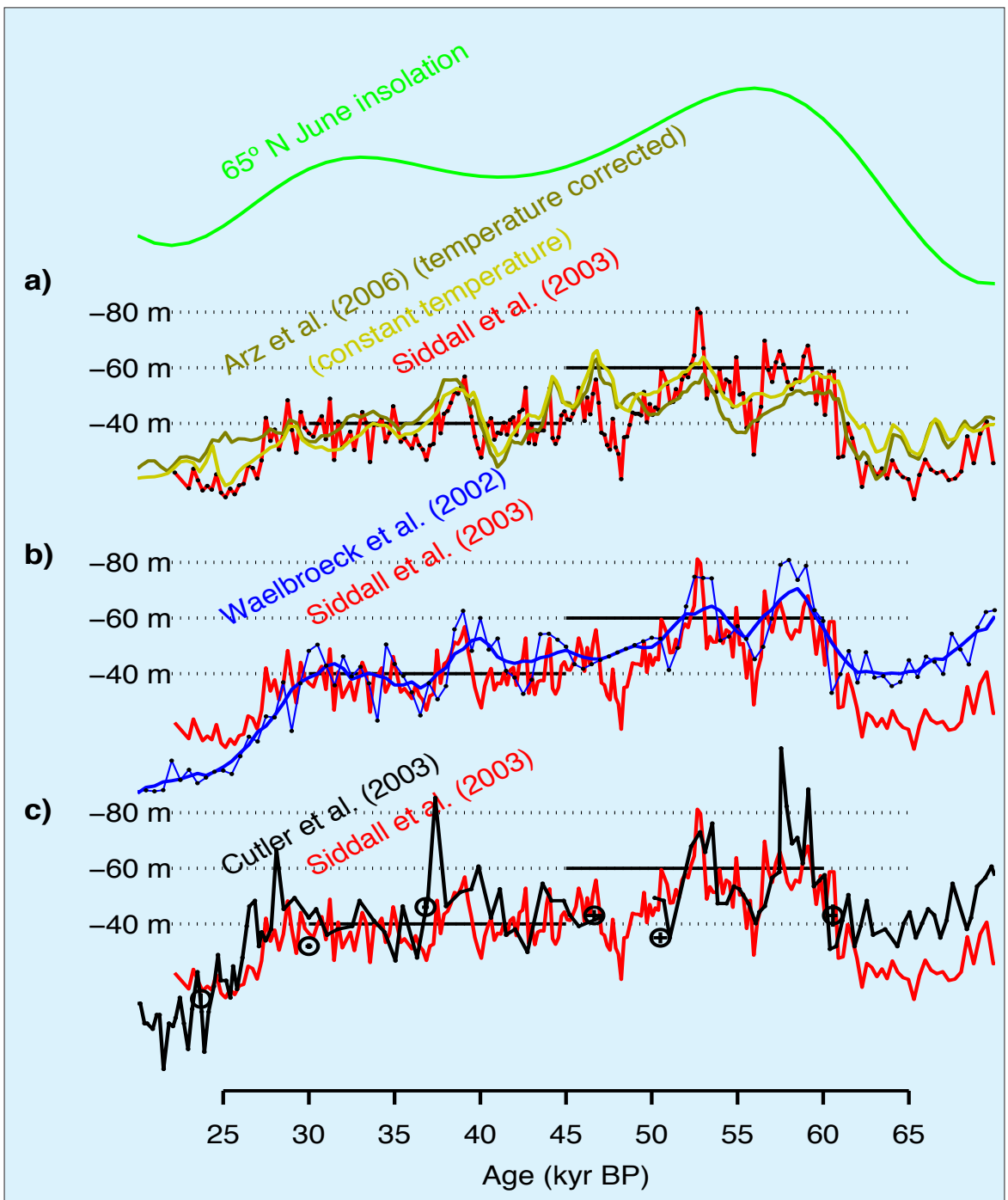

Figure 2: a) Comparison (on an arbitrary timescale) of the Siddall et al. (2003; red line) Red Sea sea level curve (based on central Red Sea planktic oxygen isotopes) with curves of Arz et al. (2007; light and dark brown curves) (based on northern Red Sea benthic oxygen isotopes). $\boldsymbol{b}$ ) and c) Estimates of sea level based on benthic isotopes calibrated to coral indicators of sea level from Waelbroeck et al. (2002; blue line) and Cutler et al. (2003; black line), respectively. Coral sea level indicators used (black circles with crosses to indicate uncertainty) are shown alongside the Cutler et al. (2003) curve. Black lines at -60 m and -80 m indicate 'typical' estimates for early and late periods of MIS 3, respectively. Published sensitivities are: Siddall et al. (2002) $\pm 12 \mathrm{~m}$, Arz et al. (2007) $\pm 12 \mathrm{~m}$ (without temperature correction) and $\pm 8 \mathrm{~m}$ (with temperature correction), and Waelbroeck et al. (2002) $\pm 13 \mathrm{~m}$.

metric cycles during MIS 3 (like Antarctic temperature), and the evidence presented by the phasing of the benthic oxygen isotope record off Portugal (Shackleton et al., 2000), suggests that during MIS 3 , ice volume varies on an Antarctic rhythm (Siddall et al., 2003; Rohling et al., 2004). This, however, is a matter of debate (Arz et al., 2007), which will no doubt form the subject of much further research (e.g., Siddall et al., subm.).

*This uncertainty margin takes meteorological variables into account, by assuming modern maxima and minima as the annual average values, such that a temperature uncertainty is allowed of $\pm 2^{\circ} \mathrm{C}$, while evaporation uncertainties allow a range from 1.4-2.8 $\mathrm{m} \mathrm{yr}^{1}$, and relative humidity varies between 60-80\%. All uncertainties were combined into a worst-case scenario to obtain the largest estimate of the sea-level uncertainty (i.e., no natural covariations were taken into account, which - if accounted forwould reduce the actual range of sea level uncertainty reported for the method).

\section{Acknowledgements}

We thank the following people for their generous input; Bill Thompson, Claire Waelbroeck, Christoph Hemleben, Peter Clark, David Smeed, Nick Shackleton, Wally Broecker and Andy Hogg. Mark Siddall is supported by a NERC RCUK fellowship.

\section{References}

Arz, H.W., Lamy, F., Ganopolski, A., Nowaczyk, N. and Pätzold, J., 2007: Dominant Northern Hemisphere climate control over millennialscale glacial sea-level variability, Quaternary Science Reviews, 26(3-4): 312-321.

Chappell, J., 2002: Sea level changes forced ice breakouts in the Last Glacial Cycle: new results from coral terraces, Quaternary Science Reviews, 21(10): 1229-1240.

Cutler, K.B., Edwards, R.L., Taylor, F.W., Cheng, H., Adkins, J., Gallup, C.D., Cutler, P.M., Burr, G.S. and Bloom, A.L., 2003: Rapid sea-level fall and deep-ocean temperature change since the last interglacial period, Earth and Planetary Science Letters, 206(3-4): 253-271.

Siddall, M., Rohling, E.J., Almogi-Labin, A., Hemleben, Ch., Meischner, D., Schmelzer, I. and Smeed, D.A., 2003: Sea-level fluctuations during the last glacial cycle, Nature, 423: 853-858.

Waelbroeck, C., Labeyrie, L., Michel, E., Duplessy, J.C., McManus, J.F., Lambeck, K., Balbon, E. and Labracherie M., 2002: Sea-level and deep water temperature changes derived from benthonic foraminifera isotopic records, Quaternary Science Reviews, 21 : 295-305.

For full references please consult:

www.pages-igbp.org/products/newsletter/ref2008_1.htm| 